Chapter II

\title{
THE SCIENTIST'S CONCERN: KNOWLEDGE FOR ITS OWN SAKE
}

Charles Peirce is not in agreement with the lexicographers' description of science as "systematized knowledge." For Peirce, science is best described as the pursuit carried on by scientific men. Genuine science is a living thing continually growing and developing (1.232). It must not be thought of as a mere collection of established truths. Rather, an intelligent conception of science "as a living historic entity must regard it as the occupation of that peculiar class of men, the scientific men" (1.99).

In the introduction to his projected "History of Science," Peirce asserts that the lexicographer and the non-scientist may regard science as an "organized body of knowledge"; but the genuine scientist regards his pursuit as a "mode of life." ${ }^{1}$ And in the course of the same work, he makes another quick reference to the same description of science, and then portrays at length the kind of spirit which should guide the scientist. Science is the pursuit of scientific men, and this pursuit must be motivated by the pure love of knowledge for its own sake.

If we are to define science $\ldots$ in the sense of characterizing it as a living historic entity, we must conceive it as that about which such men as I have

${ }^{1}$ The notes for this chapter begin on page 159. 
described busy themselves. As such, it does not consist so much in knowing, nor even in "organized knowledge," as it does in diligent inquiry into truth for truth's sake, without any sort of axe to grind, nor for the sake of the delight of contemplating it, but from an impulse to penetrate into the reason of things. . . . It is not knowing, but the love of learning, that characterizes the scientific man. . . . If a man burns to learn and sets himself to comparing his ideas with experimental results in order that he may correct those ideas, every scientific man will recognize him as a brother, no matter how small his knowledge may be.

But if a man occupies himself with investigating the truth of some question for some ulterior purpose, such as to make money, or to amend his life, or to benefit his fellows, he may be ever so much better than a scientific man, ... but he is not a scientific man [1.44f].

An understanding of what science is, therefore, can be achieved only by understanding what the scientist is about. In grasping this it will be unmistakably clear that for Peirce the motive of the scientist is of primary importance: he must be in search of knowledge for its own sake. This, of course, means that the questions asked by the scientist, and the answers which he hopes to find, will be theoretical. Accordingly, the method that he follows will be adapted to the scientist's theoretical questions.

Hence the present chapter will consider scientific inquiry as the pursuit of truth for its own sake. Scientific doubt and belief, and the pragmatic method of scientific inquiry itself, will then appear as theoretical in character. ${ }^{2}$ Only in the subsequent chapters will the details of the method be examined.

The divisions of the present chapter are not sharply distinct. Certain considerations occur in both parts, since the chapter has a single topic: the scientist's concern with knowledge for its own sake.

I. THE SCIENTIST'S SPIRIT: THE PURE LOVE OF KNOWLEDGE

The scientist animated by the pure love of truth, pursues knowledge for the sake of knowledge alone. ${ }^{3}$ Understanding science as a pursuit of a certain class of men, Peirce points out in an article dealing with the great scientists of the nineteenth century that the distinctive character of men like Darwin, Wallace, Joule, Bernouli, Helmholtz, and Mende- 
leef was their "devotion to the pursuit of truth for truth's sake." 4 They regarded science, not as something printed in books, or as systematized knowledge, but as a way of life. For men of science achievement is not the primary consideration. What is primary is the spirit that guides the work. ${ }^{5}$

In their pursuit of learning for its own sake scientists are distinguished from other classes of men. ${ }^{6}$ For scientists nature is a cosmos, "something great, and beautiful, and sacred, and eternal, and real" (5.589). They are out to learn the truth about the ways of nature, for the sake of learning, and for no other motive. If the quest for truth is motivated by any other purpose than the sheer desire for knowledge, the endeavor cannot belong to the realm of science.

Not only is there a distinction between scientists and practical men, but there is even a certain opposition. The practical man is concerned with action and results. And so, in order to act, he must believe "with all the force of his manhood" that the object of his action is good, and that his plan of action is right. ${ }^{7}$ But the scientist is so interested in truth that he is willing to reject his present beliefs if experience demands this. "This is the reason that a good practical man cannot do the best scientific work. The temperaments requisite for the two kinds of business are altogether contrary to one another" $(6.3) .{ }^{8}$ The practical man cannot hope to understand what the scientist is about, unless he undergoes an intellectual rebirth. ${ }^{9} \mathrm{He}$ will not give probable reasoning the value that the scientist must give it, and he will tend to regard science as a guide to conduct, and hence will try to find in science the practical certainty that conduct requires. ${ }^{10}$ "If a proposition is to be applied to action, it has to be embraced, or believed without reservation. There is no room for doubt, which can only paralyze action. But the scientific spirit requires a man to be at all times ready to dump his whole cartload of beliefs, the moment experience is against them" (1.55). Science, then, is the pursuit of theoretical knowledge, lived by men whose temperament is quite the opposite of that required for practical goals.

In a short passage from a work entitled "On Detached Ideas in General and on Vitally Important Topics," composed around 1898, Peirce explains with vivid clarity the primacy of the theoretical aspects of science, as well as his attitude toward those disciplines that are at once theoretical and practical: 
Even if a science be useful-like engineering or surgery-yet if it is useful only in an insignificant degree as those sciences are, it still has a divine spark in which its petty practicality must be forgotten and forgiven. But as soon as a proposition becomes vitally important-then in the first place, it is sunk to the condition of a mere utensil; and in the second place, it ceases altogether to be scientific, because concerning matters of vital importance reasoning is at once an impertinence toward its subject matter and a treason against itself [1.671].

The scientist, therefore, must put his whole person into the pursuit of theoretical knowledge; he cannot serve the two masters, theory and practice, as Peirce says. Rather he must put aside the narrow point of view that practice takes, and let his inquiry be "animated by the true scientific Eros" (1.620). ${ }^{11} \mathrm{His}$ aim "is simply and solely knowledge of God's truth" (1.239). ${ }^{12}$

The motive and method of the scientist are most intimately related. The man who is animated with a truly scientific love of knowledge for its own sake is bound to come upon the right method of proceeding. At first his method may be faulty, but if the genuine scientific Eros continues to animate him, he will sooner or later make use of the correct scientific method. In a paper, entitled by Peirce "The Rule of Logic," he speaks of the self-corrective character of an inquiry motivated by the true scientific spirit.

Inquiry of every type, fully carried out, has the vital power of self-correction and of growth. This is a property so deeply saturating its inmost nature that it may truly be said that there is but one thing needful for learning the truth, and that is a hearty and active desire to learn what is true. If you really want to learn the truth, you will, by however devious a path, be surely led into the way of truth, at last. No matter how erroneous your ideas of the method may be at first, you will be forced at length to correct them so long as your activity is moved by that sincere desire [5.582].

An inquirer with the genuine scientific spirit must inevitably adopt the correct method sooner or later; and conversely, if a man approaches an inquiry with an axe to grind, his method will almost inevitably be faulty. The desire to learn must be pure, otherwise the method of inquiry will fail to ask the right questions, or it will give inaccurate replies. A diluted motive almost invariably distorts the method. 
In a lecture written in 1898 and entitled "The Logic of Events," Peirce again emphasizes the dependence of scientific method on motive. The spirit of desiring to learn, he implies, is the most necessary requirement of scientific procedure (6.5). But a good intention, though of prime necessity, is not sufficient; the scientist must actually adopt the correct method, and carry on his investigation according to it. "The man who is working in the right way to learn something not already known is recognized by all men of science as one of themselves, no matter how little he is informed" (1.235-emphasis added). But if he is following an unsuitable method, through neglect, he is not a scientific man; such neglect may reflect a lack of intelligent sincerity in the seeker's motive. Peirce cannot deny the title of scientist to a man who has an "effective rage to learn the very truth," and who follows the best methods for his time. But the rage to know must be effective-that is, the man with a sincere love of learning must make use of the best method of learning. ${ }^{13}$

Since science is a living function of scientific men, it is more an affair of spirit and method than of conclusions. ${ }^{14}$ "Mere knowledge, though it be systematized, may be a dead memory; while by science we all habitually mean a living and growing body of truth" (6.428). Peirce even goes so far (but with hesitancy) as to say that content-knowledge may not be necessary for science.

We might even say that knowledge is not necessary to science. The astronomical researches of Ptolemy, though they are in great measure false, must be acknowledged by every modern mathematician who reads them to be truly and genuinely scientific. That which constitutes science, then, is not so much correct conclusions, as it is a correct method. But the method of science is itself a scientific result. It did not spring out of the brain of a beginner: it was a historic attainment and a scientific achievement. So that not even this method ought to be regarded as essential to the beginnings of science. That which is essential however, is the scientific spirit, which is determined not to rest satisfied with existing opinions, but to press on to the real truth of nature [6.428].

It is clear, then, that for Peirce the pure love of truth is an absolutely required characteristic of the scientist. The motive will control the method, which is the life of science. And the results of the inquiry will follow from the proper use of the scientific method. "Science consists in 
actually drawing the bow on truth with intentness in the eye, with energy in the arm" (1.235). Could "intentness in the eye" refer to the purity of the scientist's motive and "energy in the arm" to the suitability of the method? In any event, science is a living process whose only purpose is "to learn the lesson that the universe has to teach it". (5.589). In a manuscript dated around 1902, Peirce gives an excellent description of science as a way of life which has as its purpose the finding of the truth, which pursues this purpose by a well-considered method founded on scientific results already ascertained by others, and which seeks cooperation in the hope that the truth may ultimately be found, even though not by the present inquirers (7.54).

\section{THE THEORETICAL CHARACTER OF DOUBT, BELIEF, AND THE PRAGMATIC METHOD}

Consistent with his position on the spirit of scientific inquiry, Peirce maintains that both the questions asked by scientists and the answers proposed by them are theoretical-i.e., they are concerned with the real truth of things, as described above. He repeatedly calls a question doubt, and an answer belief. Although doubt and belief have a wide non-scientific scope, the aim here is to understand what Peirce has to say about scientific doubt and belief, since these mark the beginning and the end of a scientific investigation, a process which he calls inquiry. As will become clearer in subsequent chapters, the method of inquiry in a scientific investigation is pragmatic, a designation which indicates the general upshot of the method but does not specify its details. ${ }^{15}$

An important but imperfect presentation of scientific doubt and belife, and of pragmatic inquiry, is found in two articles written by Peirce before the period of his greatest productivity. ${ }^{16}$ The importance of these two articles can be judged from the following facts: ${ }^{17}$ 1.) they were the first published enunciation of the importance of doubt and belief, and of the pragmatic maxim; ${ }^{18}$ 2.) during his later years he made repeated reference to these two articles, undertook several revisions of them as the editors of the Collected Papers testify, repeatedly quoted from them, and continually expanded his understanding of the 
pragmatic method of sciences, using the two articles as a point of departure. ${ }^{19}$

In "The Fixation of Belief," Peirce attributes the eagerness for learning the truth to the dissatisfaction which doubt causes in a man. In the same article he describes doubt as "an uneasy and dissatisfied state from which we struggle to free ourselves and pass into the state of belief" (5.372). The struggle Peirce terms inquiry, and he asserts that the only purpose of inquiry is the removal of the irritating stimulus of doubt which is the same as the attainment of belief. ${ }^{20}$ This state he also describes as "the settlement of opinion" (5.375). Inquiry therefore begins with doubt, and ends with belief (5.375f).

In the second of the two early works, "How to Make Our Ideas Clear," Peirce is somewhat critical of the above.

It was there noticed ["The Fixation of Belief"] that the action of thought is excited by the irritation of doubt, and ceases when belief is attained; so that the production of belief is the sole function of thought. All these words, however, are too strong for my purpose. It is as if I had described the phenomena as they appear under a mental microscope [5.394].

This is not a serious revision of the views expressed in the earlier article. Doubt and belief are still the start and the resolution of any question (5.394). Thought still has "for its sole motive, idea and function," the production of belief. "Thought in action has for its only possible motive the attainment of thought at rest" (5.396).

What he objects to is the understanding of doubt as an irritant; this is too strong a word for doubt (5.394). And an even more important shortcoming of the first article is the understanding of belief as the close of inquiry. Belief, as the second article explains, is only a "demicadence which closes a musical phrase in the symphony of our intellectual life." Thought relaxes when belief is reached, but the rest is only momentary. Belief is not only a stopping-place; "it is also a new starting-place for thought" (5.397).$^{\mathbf{2 1}}$

Peirce's main interest in the two articles of 1877 is the presentation of the doubt-inquiry-belief procedure in scientific matters. The evidence for this is found chiefly in his presentation of the intellectual and conditional character of the pragmatic maxim and in the descrip- 
tion and evaluation of the four methods of fixing belief which have been commonly used. ${ }^{22}$

After brief mention of the genuineness of the doubt which opens a scientific inquiry, I shall explain the theoretical nature of the pragmatic maxim. Although the method is directed toward action-hence the name pragmatic-it is nevertheless theoretical, since its relation to action is decidedly different and even opposed to the relation of practice to action, as will become evident.

Rejecting the spirit of Cartesianism, Peirce makes it clear in "The Fixation of Belief," that inquiry begins with genuine doubt. The scientist must not begin by doubting everything, or by pretending to doubt anything. Rather, doubt must be real and living (5.376).

The same position on the genuineness of doubt recurs in the later writings with no notable development. The scientist's theoretical doubt usually begins with a surprise. A puzzling event occurs which incites the man of science to inquire into its explanation. But, whether surprising or not, the origin of doubt is always external. One cannot simply will to begin to doubt (5.443)..$^{23}$ A belief-habit that could be broken by will, would not be a genuine belief-habit. The "Critical Commonsensist" (which Peirce claims to be) regards the Cartesian view of supposing that one can doubt at will as an impossibility; only experience can give rise to doubt (5.524).$^{24}$ An inquiry inaugurated by a make-believe doubt will be an idle farce $(5.376 n)$.

Doubts, which arise spontaneously in the curious mind faced with experiences, that are not wholly comprehended, are to be respected, and even anticipated with eagerness. The scientist has a sacra fames for real doubt. "Only, his hunger is not to be appeased with paper doubts: he must have the heavy and noble metal, or else belief" (5.514). ${ }^{25}$

Running through the two articles of 1877 and 1878 is the theme that belief, whether scientific or not, is always directed toward action. Doubt leaves a man perplexed and unable to act. ${ }^{26}$ But "the essence of belief is the establishment of a habit; and different beliefs are distinguished by the different modes of action to which they give rise" (5.398). Belief involves the establishment of a rule of action, which, though not absolutely permanent, is still not completed in a single operation of assent. Some years later, around 1902, he wrote that a habit is a specialization of nature such that a man "will always tend to behave, in 
a way describable in general terms upon every occasion (or upon a considerable proportion of the occasions) that may present itself of a generally describable character" (5.538). ${ }^{27}$ The feeling of satisfaction which accompanies belief indicates more or less surely that a habit which will determine action has been established. One who has reached a state of belief will not necessarily act at once, but will be ready to act when the circumstances which occasioned the doubt arise. "The whole function of thought is to produce habits of action" (5.400). ${ }^{28}$

Although all beliefs are related to action, it would be a serious mistake to interpret Peirce as holding that all belief is practical. There are beliefs which are practical, and beliefs which are theoretical. He distinguishes between practical and theoretical doubt and belief in his article "How to Make Our Ideas Clear." The man who must decide to pay a horsecar fare with five pennies or with a five-cent piece is faced with a practical doubt, however insignificant it may be. The doubt and the decision solving the doubt are practical - that is, they concern an action to be performed.

A more relevant example of doubt and belief is the situation of a man with time to kill in a railroad station. He already knows his destination and train, and presumably has his ticket. In order to amuse himself he compares different routes and trains, "which I never expect to take, merely fancying myself to be in a state of hesitancy." This feigned hesitancy is more like the doubt of science than is the hesitancy of the man paying his carfare. The decision about the fictitious trip is not meant to be useful; it has no practical conclusion. The mere fact that the decision is made about an action does not remove it from the realm of theory. A decision made for an action, however, is practical. ${ }^{29}$ The man in the railroad station contemplating imagined trips is dreaming about actions, but not planning to act. He is carrying on an inquiry, somewhat like the inquiry of the scientist. "Feigned hesitancy, whether feigned for mere amusement or with a lofty purpose, plays a great part in the production of scientific inquiry" (5.394). In solving the doubt, we are trying to find out how we would act, not how we will act $(5.373 n) .^{30}$

The character of the imagined action is spelled out in greater detail later in the same article. There, in a context explicitly dealing with belief as the establishment of a habit of action, Peirce explains "im- 
agined action" in two ways. First, the habit of imagined action, in which belief consists, is an acknowledgment of how we would act under certain conditions. "The identity of a habit depends on how it might lead us to act, not merely under such circumstances as are likely to arise, but under such as might possibly occur, no matter how improbable they may be" (5.400). The other understanding of imagined action is more relevant to scientific procedure. It consists in imagining what sensible experiences we would undergo in certain conditions. In other words, we imagine what sensible effects certain things would have on us. And our apprehension of the conceived sensible effects of anything is our whole idea of that thing. "Our idea of anything is our idea of its sensible effects" (5.401). In this case our "action" is exclusively related to sensible qualities; it is, as Buchler points out, an experimental term, and not biographical or moral. ${ }^{31}$ These two types of conceived action-how we would act and how things would affect our senses-are the only types which can enter into theoretical belief, for, as Peirce explicitly says, our action, habit, belief, and conception have "exclusive reference to what affects the senses" (5.401). ${ }^{32}$

It is important to notice that in both types of imagined action employed in scientific inquiry, a conditional resolution is involved. ${ }^{33}$

After a rather rambling presentation of doubt and belief, the article "How to Make Our Ideas Clear," reaches its climax in a tightly constructed rule which the editors have labeled "The Pragmatic Maxim." 34 "Consider what effects that might conceivably have practical bearings, we conceive the object of our conception to have. Then our conception of these effects is the whole of our conception of the object" (5.402). The maxim is an early and crude summary of Peirce's views on the connection between belief and the conceived sensible effects of the objects of belief.

In a letter to William James dated November 25, 1902, Peirce admits the crudity of his understanding of pragmatism in 1877 (8.255). The refinement came later, when he saw that logic is dependent on ethics, and ethics on aesthetics, and that these three normative sciences, as he called them, correspond to his three categories. The inexact identification of meaning with action-reaction, expressed in the 1877 and 1878 papers, is later corrected by the understanding of action-reaction in terms of purpose, which is essentially thought. Vincent Potter correctly 
sees that "the acknowledgment of the role of ends in action is the insight into the role of the normative sciences, and this acknowledgment brought about Peirce's successive attempts to formulate the pragmatic maxim in a more sophisticated and adequate way." 35

One such sophistication was the insistence that meaning is intellectual purport, as Peirce wrote in 1906. He refers to his stylistic habit of avoiding repetition of a word; and then he notes that in the maxim's five lines, the word "conception" or a cognate appears five times. This, he says, has two purposes: "One was to show that I was speaking of meaning in no other sense than that of intellectual purport. The other was to avoid all danger of being understood as attempting to explain a concept by percepts, images, schemata, or by anything but concepts." Action is the end of thought, not in that it is the purpose of thought, but rather that action is the object of thought: it is that about which the thinker thinks. Thought applies to action exclusively-to conceived action, as Peirce emphatically states $(5.402 n 3)$. Thought is not necessarily for action. It is about action.

That the pragmatic maxim is designed to clarify intellectual purport is brought out again in the "Issues of Pragmaticism," where Peirce makes reference to the earlier phrasing of the maxim in "How to Make Our Ideas Clear." In the "Issues," he notes that the maxim can be restated in the indicative mood, but with the same stress on theoretical knowledge. "The entire intellectual purport of any symbol consists in the total of all general modes of rational conduct which, conditionally upon all the possible different circumstances and desires, would ensue upon the acceptance of the symbol" (5.438). As Gallie points out, Peirce's proposal to clarify the meaning of a concept by considering all its practical consequents is an impossible ideal. ${ }^{36}$ However, it is clear that what the pragmaticist is interested in is theoretical knowledge. His pragmaticism is merely an attempt to devise a "method of determining the meanings of intellectual concepts" (5.8f).

The same view of pragmatism is brought out in a letter to William James, written by Peirce in 1902:

Pragmatism is correct doctrine only in so far as it is recognized that material action is the mere husk of ideas. The brute element exists, and must not be explained away. . . . But the end of thought is action only in so far as the 
end of action is another thought. Far better to abandon the word "thought," and talk of "representation," and then define what kind of a representation it is that constitutes consciousness. ${ }^{37}$

The true pragmatist is interested in rational meaning, which consists in experimental phenomena, in "what surely will happen to everybody in the living future who shall fulfill certain conditions," as he wrote in 1905 (5.425). The pragmaticist scientist is interested in certain kinds of experimental phenomena. What he tries to imagine in his pragmatic method is something of a certain character. Hence it is a misrepresentation to say that for him rational meaning consists in an experiment. An experiment is a single event. Its individuality is of no interest to the pragmaticist scientist, as it must be to the man of practical action. ${ }^{38}$ Thought expects a certain kind of event to occur under given conditions. ${ }^{39}$

Expectation seems to be an important element of Peirce's pragmatism. Knowledge must involve a reference to experience; and this reference is an expectation, an imaginary (in the case of theoretical knowledge) anticipation of experience. "Knowledge which should have no possible bearing upon any future experience-bring no expectation whatever-would be information concerning a dream. But in truth no such thing can be presumed of any knowledge" (5.542). Even the distinction between practical belief and theoretical belief can be explained in terms of expectations. Practical belief is expectant of muscular sensation, and a kind of tension of the striped muscles. Theoretical belief, or, as Peirce calls it here, "an expectation so far as it involves no purpose [or] effort," is expectant of sensation that is not muscular (5.540).

It would be wrong to think that the pragmatic method is merely a way of clarifying meaning independently of any assertion of truth. While a certain amount of pragmatic clarity is a prerequisite to assertion, as Thompson and Murphree point out, the pragmatic method in its fullness is nevertheless a way of grasping truth. ${ }^{40}$ In a scientific context, the method is designed, as we shall see in the subsequent chapters, to lead gradually to a knowledge of reality. Understanding the truth in terms of pragmatic meaning is for the man of science a unified process in which clarity of meaning is not divorced from assertions of truth. The pragmatistic method, therefore, is directed toward theoretical 
knowledge, intellectual purport. In accordance with this method, conceived actions or experiences are both conditional and general. In other words, the scientist understands reality by representing to himself what type of event would occur under certain conditions (5.528).

It will become more evident in the later chapters that scientific inquiry is pragmatic. What is not so evident, however, is that the method, though adequate to clarify some ideas and to fix some beliefs, can qualify as a general method for unfolding all theoretical meaning. The articles of 1877 and 1878 claim not only to provide a method of intellectual clarification of concepts used in the natural sciences, but also to promote the use of the very same method in any theoretical inquiry. W. B. Gallie detects an ambiguity in Peirce's pragmaticism:

Either it is a general maxim of logic, applicable doubtless in rather special (specially precise) ways to scientific expressions; or else it is that criterion of the distinctness of different scientific expressions, whose applicability distinguishes these expressions as a class or genus from other forms of expression -with the implication that these others, to which Pragmatism does not apply, should be rejected as meaningless or recast to conform to scientific standards. ${ }^{41}$

Peirce recognized the difficulty, Gallie asserts, and preferred, though not exclusively, to adhere to the more restricted application of the pragmatic method. But this was really not a satisfactory solution, because he never gave up the quest for a single, simple method to settle all theoretical doubt. The narrower application of the method to problems in the natural sciences is highly satisfactory, because what a natural scientist-at least in Peirce's day-should seek can be expressed in terms of the conceivable experimental phenomena which the scientific expression would imply. It is especially in this narrower sense-sc., as a procedure of the natural scientist-that Peirce's pragmatic method will be studied in the following pages.

In a lecture written in 1898 Peirce sums up some of the main topics of this chapter. He says of scientific method that it must start from doubt or an interrogation. Such an interrogation is an admission that we do not know something, an implicit desire to know it, and an effort to discover what the truth really is. If that interrogation inspires 
the seeker, he will examine the instances; if it does not, he will pass them by without attention (5.584).

It is the scientist's motive, the pure love of theoretical knowledge, that makes him different from other men, and that controls his work: His concern for theoretical knowledge will lead him inevitably to choose the best method for attaining such knowledge; this choice is itself a scientific achievement (6.428). The details of the method will be treated in the chapters which follow. 